\section{Penggunaan Lapisan CTRB Dalam Peningkatan Struktur Jalan Ruas Jalan Batas Kota Muara Teweh - Malawaken - Benangin - Lampeong - Batas Propinsi Kalimantan Timur}

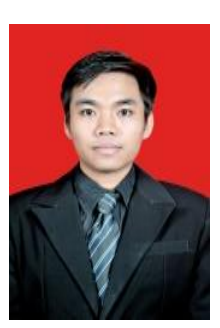

\section{ANTONIUS EVENDRI}

Antonius Evendri, Tenaga Teknis konsultan perencanaan dan pengawasan. buletinppi@ulm.ac.id
Perkerasan jalan merupakan salah bagian dari kontruksi jalan. Salah satu inovasi dalam penghematan biaya maka digunakan metode Cement Treated Recycling Base (CTRB) dalam pekerjaan lapisan pondasi jalan. Ruas jalan Benangin-Lampeong-Batas Propinsi Kalimantan Timur merupakan jalan nasional trans Kalimantan sehingga perlu adanya peningkatan dan perhatian dalam perbaikan struktur jalan guna menunjang kelancaran transportasi lintas Kalimantan. Hasil Uji UCS CTRB sesuai DMF berturut-turut $26,40 \mathrm{~kg} / \mathrm{cm}^{2}$, $30,90 \mathrm{~kg} / \mathrm{cm}^{2}, 35,49 \mathrm{~kg} / \mathrm{cm}^{2}$ untuk kadar semen $5,5 \%$, 7,5\%, 9,5\% dan Hasil Uji UCS CTRB sesuai JMF berturutturut $\quad 19,27 \mathrm{~kg} / \mathrm{cm}^{2}, \quad 23,12 \mathrm{~kg} / \mathrm{cm}^{2}, \quad 27,91 \mathrm{~kg} / \mathrm{cm}^{2}$, $32,81 \mathrm{~kg} / \mathrm{cm}^{2}$ untuk kadar semen $5 \%, 6 \%, 7 \%, 8 \%$. Kadar semen yang digunakan untuk pekerjaan CTRB sebesar 7,5\% sesuai hasil data DMF dan JMF dimana nilai Kuat Tekan Bebas (KTB) memenuhi standart $30 \mathrm{~kg} / \mathrm{cm}^{2}$ yang sesuai dengan speksifikasi khusus CTRB berdasarkan Standar Nasional Indonesia (SNI).

www.buletinppi.ulm.ac.id

\section{Pendahuluan}

Perkerasan jalan adalah suatu bagian dari jalan yang diperkeras dengan lapisan konstruksi tertentu yang memiliki ketebalan, kekakuan, kekuatan dan kestabilan tertentu sehingga mampu mentransfer beban lalu lintas yang melintas di atasnya ke lapisan tanah dasar. Dengan kombinasi agregat dan proses pencampuran aspal yang optimal akan mengasilkan suatu lapis perkerasan jalan yang kuat dan memiliki waktu layak yang panjang.

Salah satu inovasi pada teknologi perkerasan jalan raya yang dihasilkan adalah teknologi dalam proses pencampuran aspal menggunakan bahan daur ulang yang berasal dari pengupasan sisa perkerasan lama yang dikombinasikan dengan bahan yang baru ditinjau dari pertimbangan ekonomi dan lingkungan.

Cement Treated Recycling Base (CTRB) adalah teknologi stabilisasi pondasi jalan dengan system daur ulang campuran dingin pada perkerasan jalan. Material yang didaur ulang dengan campuran dingin ini umumnya dimanfaatkan dari material yang sudah ada di perkerasan lama dan digunakan sebagai lapis pondasi atas/Cement treated Recycling Base (CTRB). Lapis pondasi agregat semen adalah suatu jenis lapi perkerasan yang menggunakan semen Portland sebagai bahan pengikat.

Pengembangan teknologi daur ulang campuran dingin ini diharapkan tidak hanya memperbaiki lubang atau kerusakan yang terjadi tetapi juga memperkuat struktur jalan agar lebih tahan lama dan tidak mudah rusak kembali. Dengan teknologi daur ulang campuran dingin aspal bekas dari jalan yang rusak, dapat membuat kekerasan mendekati beton, tetapi jalan lebih lentur. Sehingga jika tanah dasarnya turun, maka aspalnya ikut turun. Sedangkan jika menggunakan beton, jika tanah dasarnya turun, maka akan retak sehingga jalan beton tersebut harus dibongkar. Hal ini jelas menambah biaya, tenaga dan waktu sehingga dinilai kurang efisien. Dengan adanya teknologi daur ulang campuran dingin maka hanya tanah dasarnya saja yang akan diperbaiki dan diberi perkeras.

Pengaruh penambahan semen terhadap nilai UCS untuk meningkatkan mutu perkerasan lama untuk digunakan sebagai lapis pondasi perkerasan jalan harus memenuhi syarat spesifikasi khusus CTRB. DMF (Desain Mix Formula) mengunakan variasi kadar semen $5,5 \%, 7,5 \%$ dan $9,5 \%$ dan UCS diperam 7 hari berdasarkan Standar Nasional Indonesia (SNI).

Lokasi pekerjaan Ruas Jalan Batas Kota Muara Teweh-Malawaken-Benangin-Lampeong-Batas

Propinsi Kalimantan Timur panjang ruas jalan $\pm 155 \mathrm{~km}$, panjang pekerjaan efektif CTRB $\pm 1,5 \mathrm{~km}$ untuk ruas jalan Benangin-Lampeong-Batas Propinsi Kalimantan Timur. Ruas jalan ini merupakan jalan nasional trans Kalimantan sehingga perlu adanya peningkatan dan perhatian dalam perbaikan struktur jalan guna menunjang kelancaran transportasi lintas Kalimantan.

\section{Hasil Kerja}

\section{Job Mix Formula pekerjaan}

Trial Perkerasan lapisan jalan CTRB dilakukan untuk membandingkan hasil DMF dan uji material dilapangan untuk mendapatkan hasil JMF (Job Mix Formula). Variasi Campuran kadar semen $5 \%, 6 \%, 7 \%, 8 \%$. Campuran dicetak pada cetakan diameter $70 \mathrm{~mm}$ dan tinggi $140 \mathrm{~mm}$ dan peram selama 7 hari kemudian dilakukan uji UCS.

\section{Hasil Perbandingan DMF dan JMF}

Hasil Uji UCS sesuai DMF berturut-turut $26,40 \mathrm{~kg} / \mathrm{cm}^{2}$, $30,90 \mathrm{~kg} / \mathrm{cm}^{2}, 35,49 \mathrm{~kg} / \mathrm{cm}^{2}$ untuk kadar semen $5,5 \%$, $7,5 \%, 9,5 \%$ dan Hasil Uji UCS sesuai JMF berturut-turut $19,27 \mathrm{~kg} / \mathrm{cm}^{2}, 23,12 \mathrm{~kg} / \mathrm{cm}^{2}, 27,91 \mathrm{~kg} / \mathrm{cm}^{2}, 32,81 \mathrm{~kg} / \mathrm{cm}^{2}$ 
untuk kadar semen $5 \%, 6 \%, 7 \%, 8 \%$. Hal ini bisa dapat dilihat pada Table 1. Hasil uji UCS.

Tabel 1. Hasil uji UCS

\begin{tabular}{|c|c|c|c|}
\hline & Kadar Semen & $\begin{array}{c}\text { Kuat Tekan Bebas } \\
\text { (KTB) }\end{array}$ & \\
\hline \multirow[t]{3}{*}{ DMF } & $5,50 \%$ & 26,40 & $\mathrm{~kg} / \mathrm{cm}^{2}$ \\
\hline & $7,50 \%$ & 30,90 & $\mathrm{~kg} / \mathrm{cm}^{2}$ \\
\hline & $9,50 \%$ & 35,49 & $\mathrm{~kg} / \mathrm{cm}^{2}$ \\
\hline \multirow[t]{4}{*}{ JMF } & $5,00 \%$ & 19,27 & $\mathrm{~kg} / \mathrm{cm}^{2}$ \\
\hline & $6,00 \%$ & 23,12 & $\mathrm{~kg} / \mathrm{cm}^{2}$ \\
\hline & $7,00 \%$ & 27,91 & $\mathrm{~kg} / \mathrm{cm}^{2}$ \\
\hline & $8,00 \%$ & 32,81 & $\mathrm{~kg} / \mathrm{cm}^{2}$ \\
\hline
\end{tabular}

Nilai KTB untuk uji UCS antara $30-40 \mathrm{~kg} / \mathrm{cm}^{2}$ sesuai setandar SNI untuk sampel cetakan diameter $70 \mathrm{~mm}$, tinggi $140 \mathrm{~mm}$ dan telah diperam 7 hari

Dalam Gambar 1. ditunjukan bahwa kondisi jalan sebelum dilakukan pekerjaan perbaikan lapisan struktur perkerasan jalan dengan menggunakan metode Cement treated Recycling Base (CTRB). Lokasi jalan pada Gambar 1. berada pada ruas jalan BenanginLampeong-Batas Propinsi Kalimantan Timur.

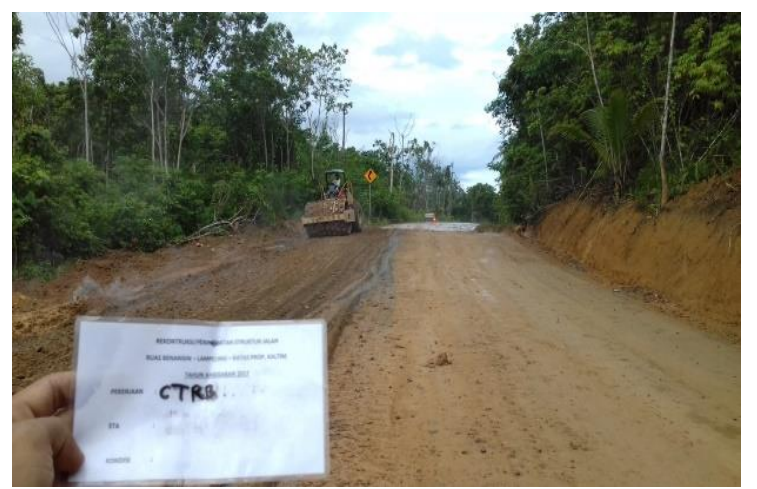

Gambar 1. Kondisi Nol Persen (0\%)

Pekerjaan pengamparan semen yang akan digunakan dalam pekerjaan Cement treated Recycling Base (CTRB) yang akan dimilling dengan menggunakan alat CTRB. Hal ini seperti ditunjukkan dalam Gambar 2.

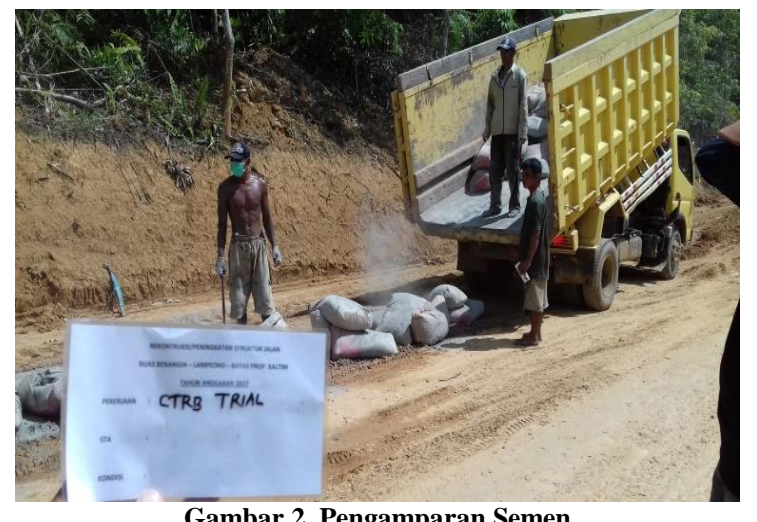

Gambar 2. Pengamparan Semen

Pekerjaan mix in place ini dikerjakan dengan menggunakan alat CTRB sambil menjaga kadar air yang dalam pekerjaan CTRB. Kegemburan campuran dijaga agar tetap berada pada ketebalan $\pm 35 \mathrm{~cm}$. Hal ini seperti ditunjukkan dalam Gambar 3.

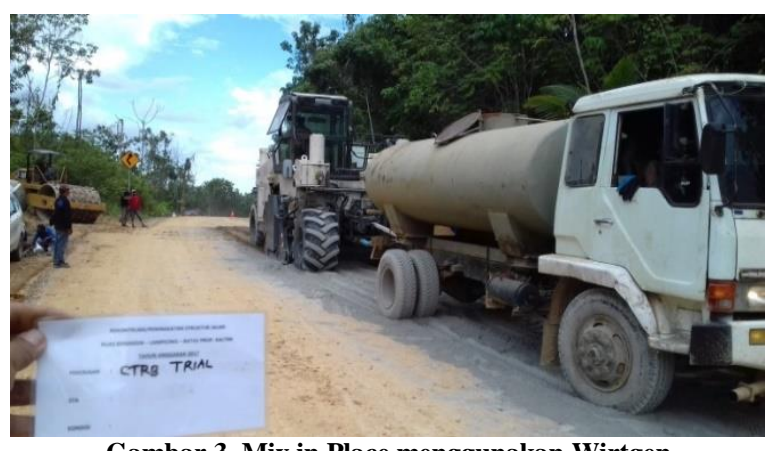

Gambar 3. Mix in Place menggunakan Wirtgen

Dalam Gambar 4. ditunjukan proses pekerjaan leveling permukaan jalan hasil milling dari alat CTRB agar bisa dipadatkan menggunakan alat pemadat Tamping Roller. Sebelum pekerjaan leveling permukaan jalan dilakukan pekerjaan cek ketebalan gembur hasil dari milling alat CTRB, ketebalan $\pm 35 \mathrm{~cm}$.

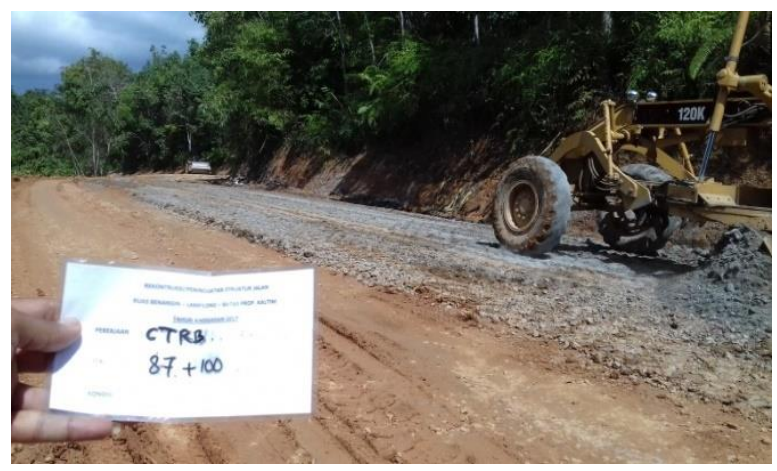

Gambar 4. Leveling Permukaan

Pelaksanaan pekerjaan pemadatan permukaan jalan hasil milling dari menggunakan alat Tamping Roller. Banyaknya Passing \pm 10 kali suai dengan hasil Trial CTRB yang dilakukan sebelum pekerjaan CTRB dilaksanakan. Hal ini seperti ditunjukkan dalam Gambar 5.

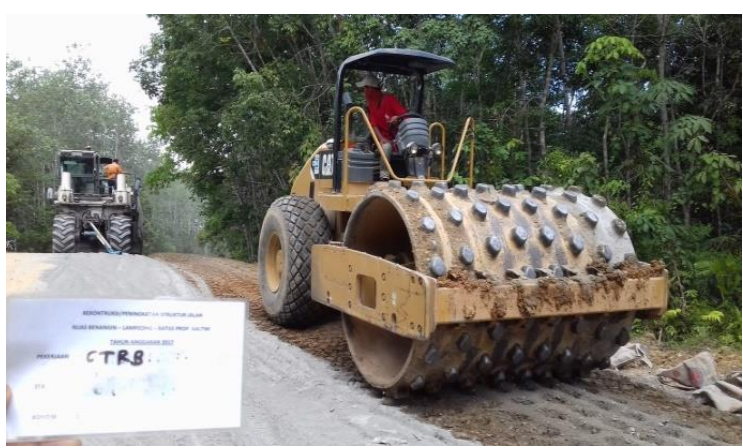

Gambar 5. Pemadatan menggunakan Tamping Roller

Pelaksanaan pekerjaan pemadatan permukaan jalan menggunakan Vibrator Roller. Banyaknya Passing \pm 8 kali menyesuaikan dengan hasil Trial CTRB yang dilakukan sebelum pekerjaan CTRB dilaksanakan. Hal ini seperti ditunjukkan dalam Gambar 6. 


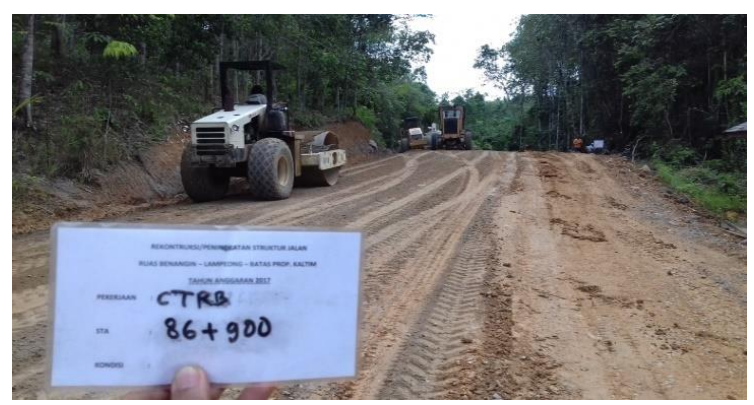

Gambar 6. Pemadatan menggunakan Vibrator Roller

Kondisi perkerasan jalan hasil pekerjaan CTRB yang telah dikerjakan pada ruas jalan Benangin-LampeongBatas Propinsi Kalimantan Timur. Hal ini seperti ditunjukkan dalam Gambar 7.

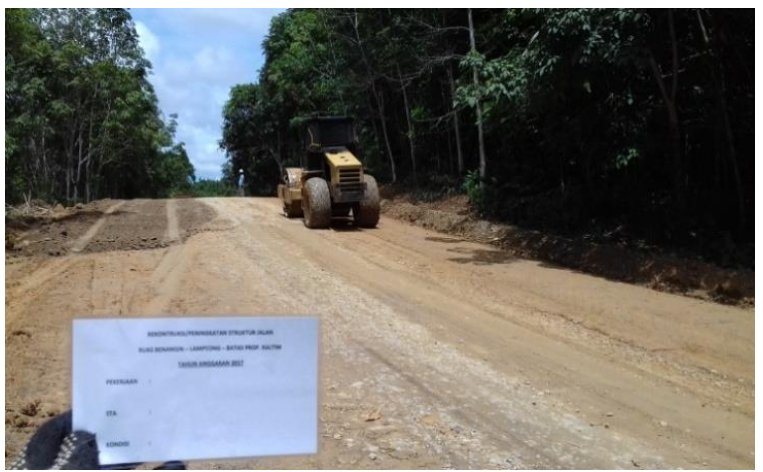

Gambar 7. Kondisi Jalan Setelah di CTRB

Pekerjaan uji sampel UCS yang dicetak pada saat pelaksaan pekerjaan CTRB. Pengujian kuat tekan bebas UCS untuk mengetahui Nilai KTB untuk uji UCS telah memenuhi nilai antara $30-40 \mathrm{~kg} / \mathrm{cm}^{2}$ sesuai setandar SNI. Pengujian tersebut dikerjakan untuk memastikan bahwa campuran dilapangan telah mememenuhi standart. Hal ini seperti ditunjukkan dalam Gambar 8.

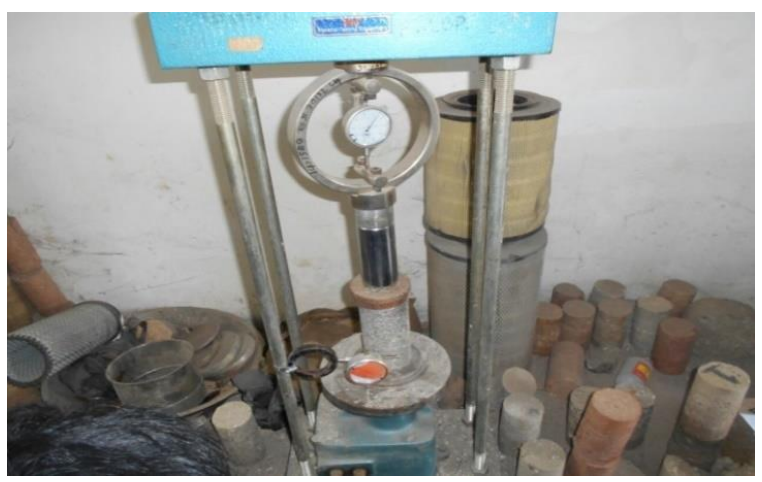

Gambar 8. Pengujian Kuat Tekan Bebas UCS

\section{Kesimpulan}

Kadar semen yang digunakan $7,5 \%$ sesuai hasil data DMF dan JMF dimana nilai Kuat Tekan Bebas (KTB) $30,90 \mathrm{~kg} / \mathrm{cm}^{2}$. Nilai KTB tersebut telah sesuai dengan speksifikasi khusus CTRB berdasarkan Standar Nasional Indonesia (SNI) dengan nilai Kuat Tekan Bebas (KTB) 30 $-40 \mathrm{~kg} / \mathrm{cm}^{2}$.

\section{Ucapan Terimakasih}

Terimakasih kepada Tuhan dan Keluarga yang selalu memberikan dukungan dan doa. Terimakasih kepada rekan-rekan Tim PW-13 yang membantu memberikan data serta memberikan masukan pemikiran dalam penulisan ini.

\section{Referensi}

1 Muda. Anastasia H, Tinjauan Tekan Bebas dan Drying Shrinkage Cement Treated Recycling Base (CTRB) pada Rehabilitasi Jalan Boyolali - Kartosuro, Tesis (2009) : 1-4.

2 Kementrian Pekerjaan Umum, Pelaksanaan daur ulang perkerasan jalan dengan semen dicampuran ditempat (inplace), Pedoman Kontruksi dan Bangunan (2010): 1-15.

3 Basuki. Rachmad, Chomaedhi dan Wildan.M.A, Perencanaan Komposisi Daur Ulang Campuran Dingin Pada Perkerasan Lama Sebagai Alternatif Peningkatan Struktur Lapisan Pondasi Atas (Studi Kasus Jalan Pantai Utara) Prosiding Seminar Nasional Aplikasi Teknologi Prasarana Wilayah (ATPW (2012): C.100-C.101. 